\title{
Weather modification is possible... is it feasible?
}

\author{
Darrel Baumgardner \\ Droplet Measurement Technologies \\ LLC (DMT)
}

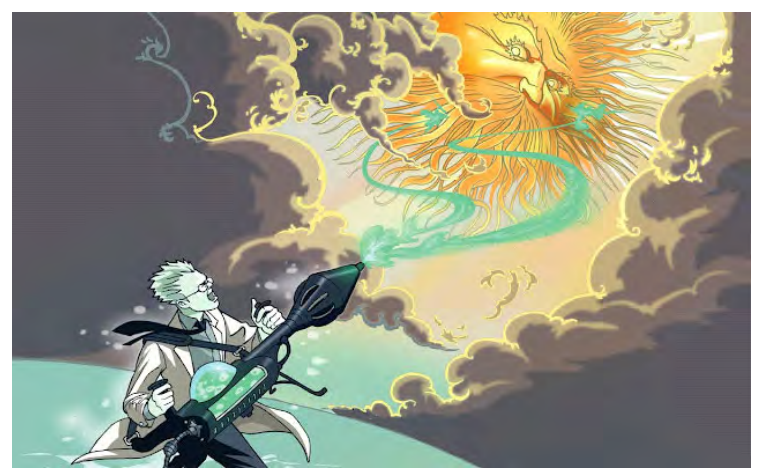

Image Credit: Adapted from original by Craig Phillips for The Wilson Quarterly

\section{Background}

Mankind has had a fascination with weather since the earliest recorded history of the human race, and an associated belief that people have the capacity to alter weather. Early religions attributed weather, i.e. wind, rain, storms, lightning, to the blessings or wrath of gods and goddesses. Through prayers, dances (e.g. Butree, 1930) or incantations (Fig. 1) the worshippers would try to influence these deities, either to provide rain so that crops would thrive or to stop the rain when flooding was a concern.

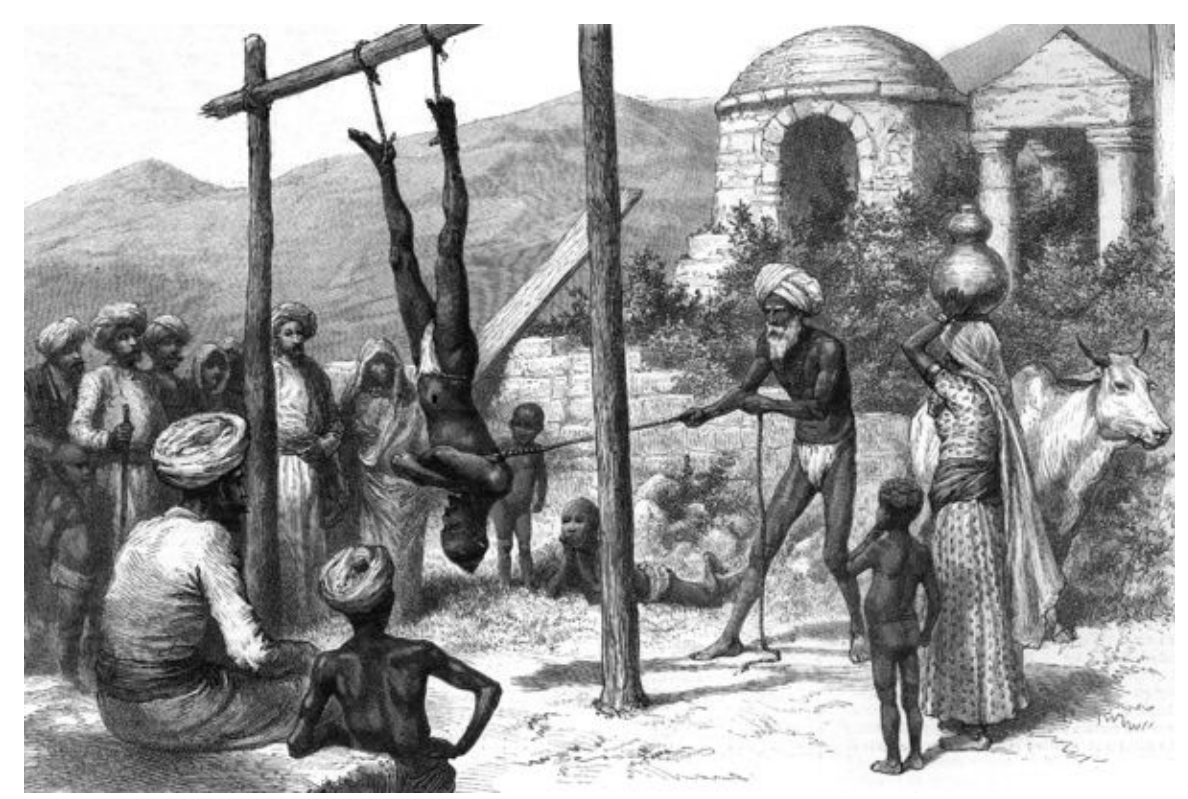

Figure 1 A fakir in India attempting to produce rain. 
Because of the severe drought in many places across the western United States, in the late $19^{\text {th }}$ and early $20^{\text {th }}$ centuries, there were many who claimed they could make rain by exploding gun powder (Fig. 2) or by evaporating mixtures of chemicals contained in large vats atop elevated towers (Brimner, 2015), Due to the desperation of farmers with failing crops, significant sums were spent on these efforts with dubious, or at least unverifiable, results.

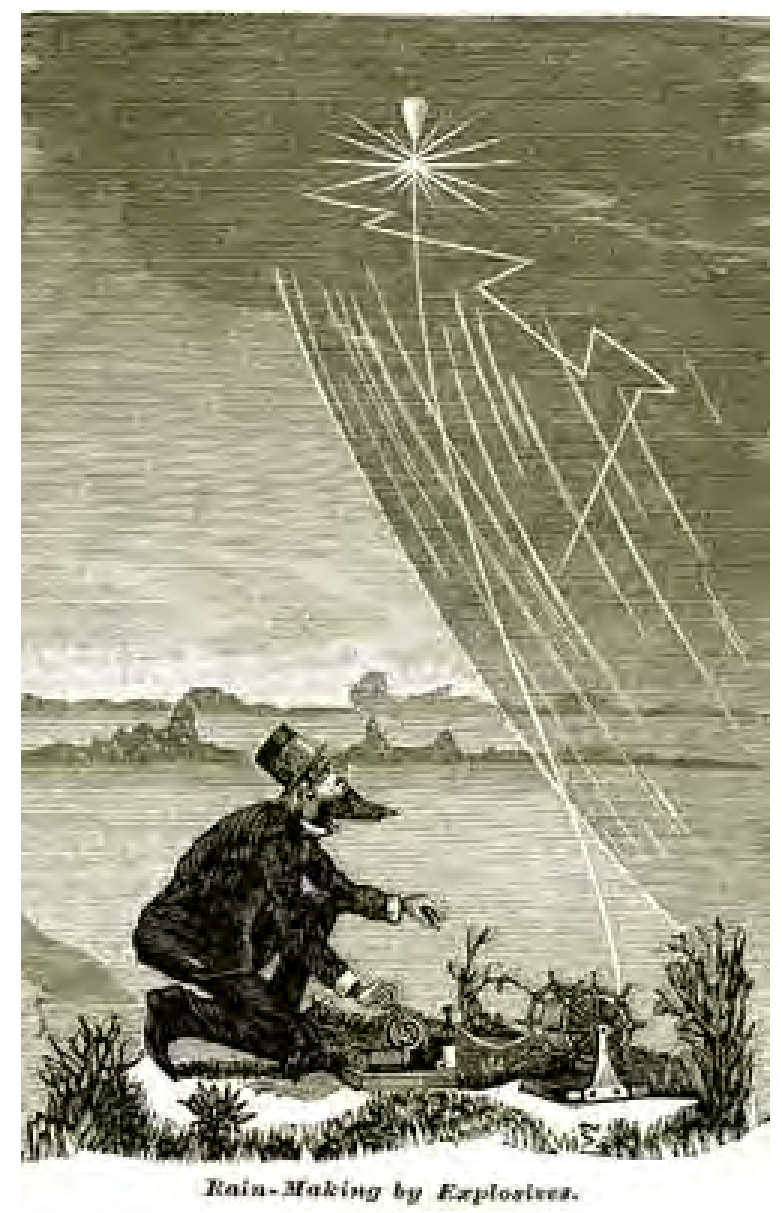

Figure 2 Rain making was attempted by exploding gun powder in the late 19th and early $20^{\text {th }}$ centuries during droughts across the western United Stated of America,

By the 1920s, with a growing understanding of how clouds form and produce rain, a program was initiated in the United States to "seed" clouds using electrically charged sand (Fig. 3) to promote precipitation. This was a fairly short-lived program and, to my knowledge, observations that could be used to assess its success were never documented in peer reviewed journals. Such results were likely written up in military reports that might be difficult to unearth. 


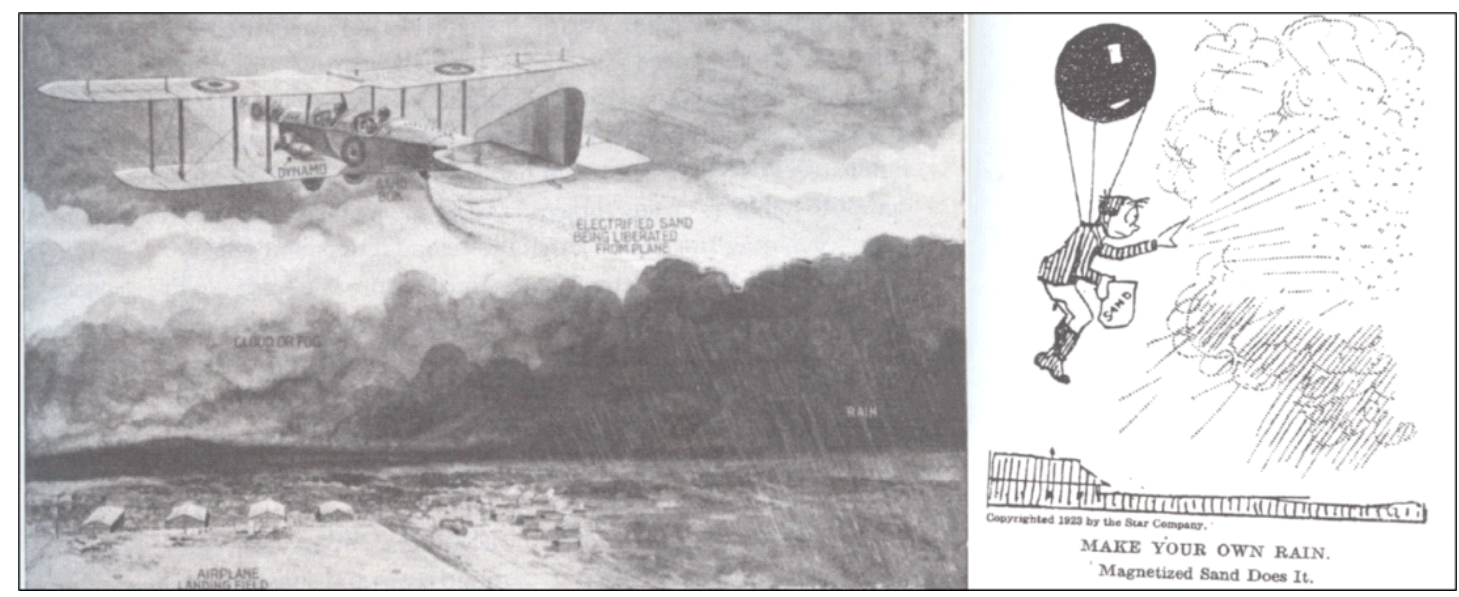

Figure 3 On the left, originally published as "Making Rain with Electrified Sand", in Science and Invention, Vol 10, 1923 (Harper, 2017). On the right, a cartoon published in Literary Digest, 1923 (Harper, 2017)

A study that received much more publicity and is considered by some in the field of weather modification to be the beginning of modern cloud seeding, was the Cirrus Project, conducted by the General Electric Company in 1946, immediately following the second world war. This effort was spearheaded by a team of scientists, Irving Langmuir, Vincent Schaefer and Bernard Vonnegut (Schaefer, 1968). In the laboratory they discovered that dry ice $\left(-90^{\circ} \mathrm{C}\right)$, produced ice crystals that seemed to form out of just humid air, but it was recognized later that the very rapid cooling brought about ice formation on aerosol particles that are classified as ice nuclei (IN). Figure 4 shows these scientists and their team loading dry ice in dispensers that were then used to release the dry ice from an aircraft into clouds. In this same figure is the very well-known photo of stratus clouds that had been seeded with this dry ice. The two linear, lighter colored clouds are where the seeding material had produced ice crystals that were subsequently removed from the cloud as their greater mass caused them to precipitate (fall from the cloud).

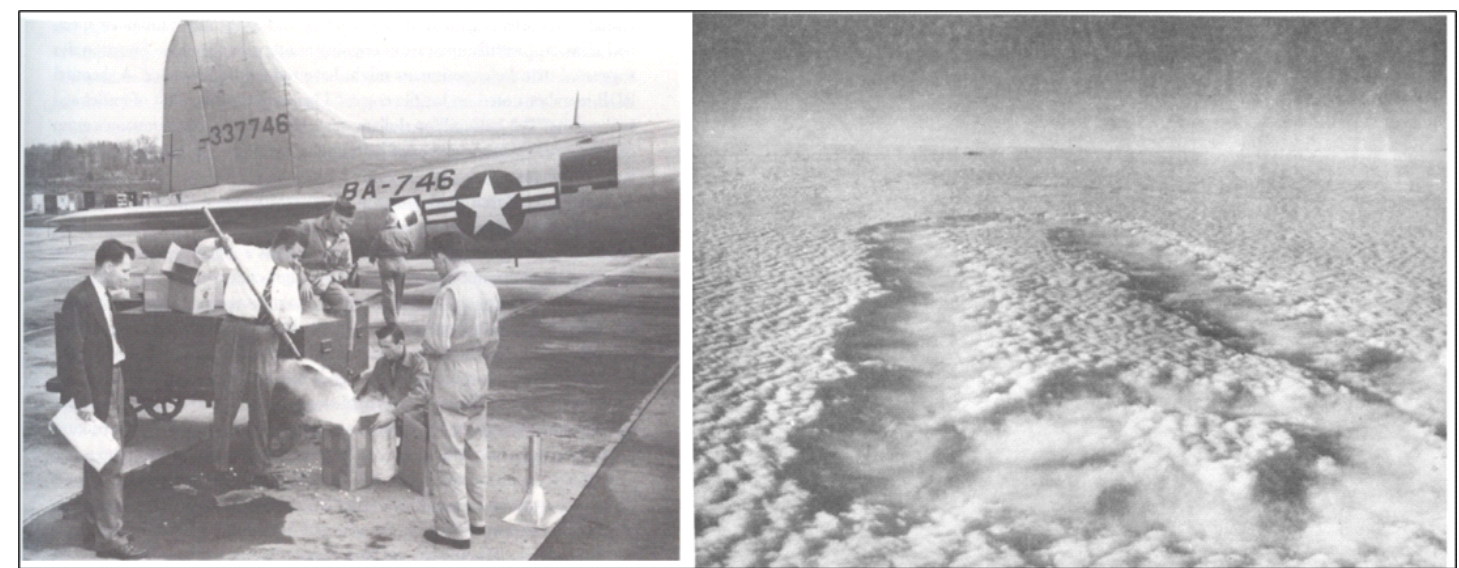

Figure 4, General Electric scientists and technicians fill dispensers with dry ice to be released from the aircraft (left). The two, linear tracks of lighter colored clouds in the 
photo to the right indicate where the dry ice had been released.

Today, cloud seeding operations continue worldwide, in more than 30 countries, including Mexico, to enhance or suppress rain, augment snow pack, mitigate damage from hail and decrease pollution. The remainder of this text describes the theoretical underpinnings of cloud seeding, points out the major obstacles to successful seeding, then concludes by addressing the titular question, "Is it Feasible?".

\section{Theoretical basis for cloud modification}

The central hypothesis of cloud seeding is the following: "The application of the appropriate seeding material will lead to a chain reaction that will produce ice crystals over a significantly larger region".

Figure 5 illustrates the complexity of processes in clouds that lead to the formation of precipitation. The actual path taken depends on the thermodynamic structure of the atmosphere, on the dynamic forcing mechanisms like convection, frontal lifting or orographic motions and on the properties of the environmental aerosol particles on which water droplets and ice crystals form.

In order to encourage the development of precipitation, on one hand, or to decrease the probability of hail formation, on the other, multiple paths must be disrupted or altered. The effectiveness of the seeding is highly sensitive, not only to where you do the seeding but when and with what material you do it.

Whereas early seeding was done with dry ice or silver iodide, Agl, in order to promote ice crystal formation, more sophisticated approaches are being pursued to encourage more rapid collision and coalescence of water droplets by introducing giant and ultra-giant cloud condensation nuclei (CCN), those aerosol particles on which water vapor condenses. However, Agl is still used in many snowpack enhancement or hail suppression programs.

The principle point to underscore is that in order to have any chance at all of changing the natural course of a cloud's development, the state of the environment must be very well characterized with a combination of measurements and modeling. Not every environmental situation is conducive for seeding and, in some cases, seeding might actually have a negative impact, as discussed further below. At the very least, prior to embarking on a seeding mission, the vertical profile of temperature, humidity and wind velocity (speed and direction) are essential data that will determine the seedability of a cloud system. In addition, if there is already an excess of CCN, the probability that adding more CCN will have the desired effect is quite low. Hence, models are needed to take these data and simulate the likelihood of the desired seeding effect with forecasts that consider all the known factors. 
In summary, effective cloud seeding must be science-driven, backed by comprehensive and accurate measurements, and coupled with models that are tuned to a specific area, i.e. plains versus mountains, tropical versus temperate or continental versus maritime. There just isn't a "one model fits all" that is available.

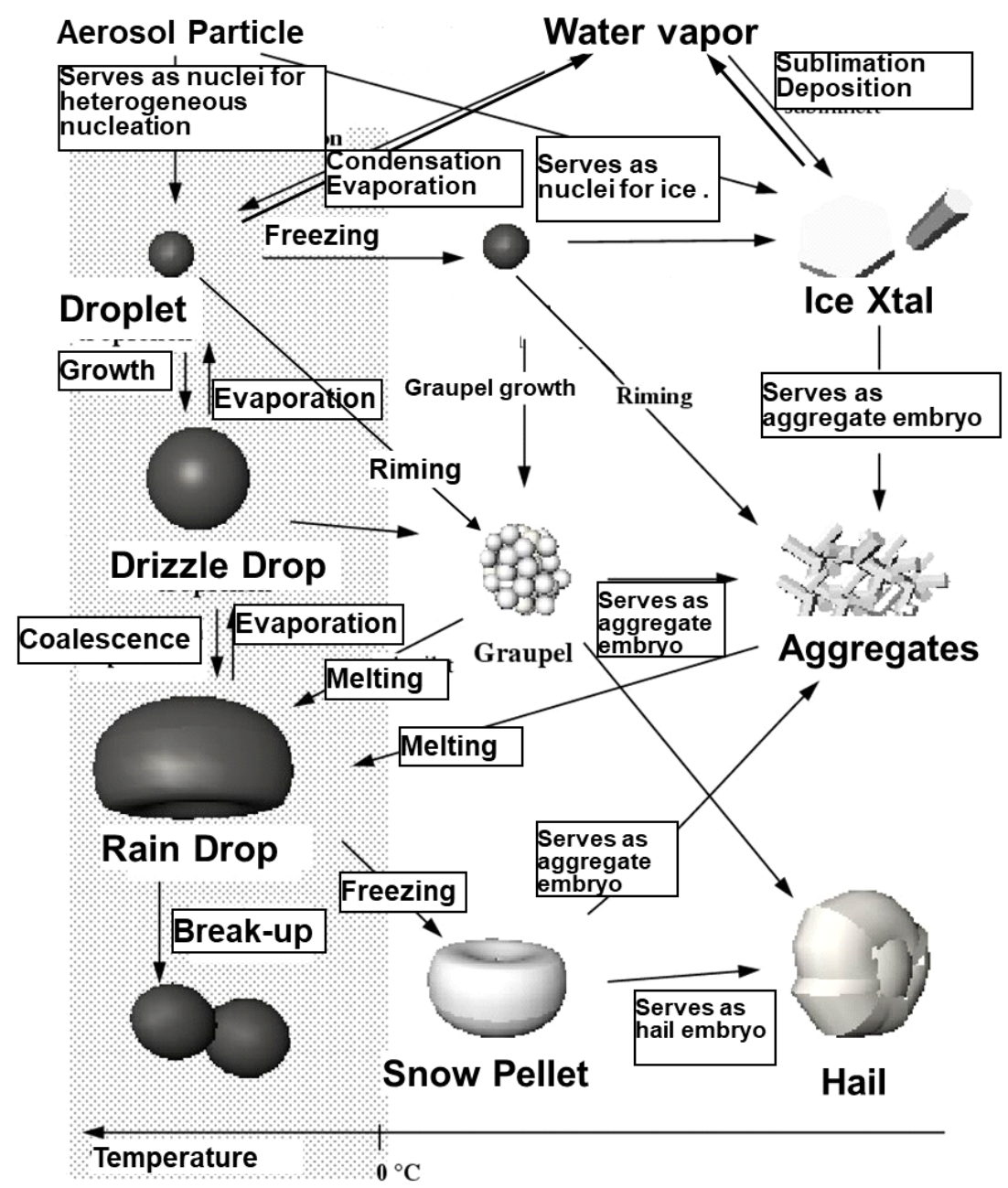

Figure 5 Pathways along which drizzle, rain, snow, graupel or hail can form, starting with water vapor and CCN or IN. Figure courtesy of Professor Stephan Borrmann, University of Mainz, Germany.

\section{Inadvertent weather modification}

One of the ironies associated with the belief of those nay-sayers who claim that climate change is not caused by human activities is that there is welldocument evidence of what is called "inadvertent weather modification" that clearly refutes that claim. Satellite images, such as the one shown in Fig. 6, reveal unquestionable proof that emissions from combustion engines, produced by ships, are modifying cloud properties. The bright lines seen 
embedded in the marine stratus are a result of increased concentrations of much smaller water droplets that formed on the pollution particles. These droplets have much higher reflectivity than the natural stratus clouds whose droplets are larger but in much lower concentrations. Although these pollutionproduced clouds might not have a significant impact on global climate, if they decrease the probability that the stratus clouds form precipitation, then they are disrupting the hydrological cycle upon which life on earth depends.

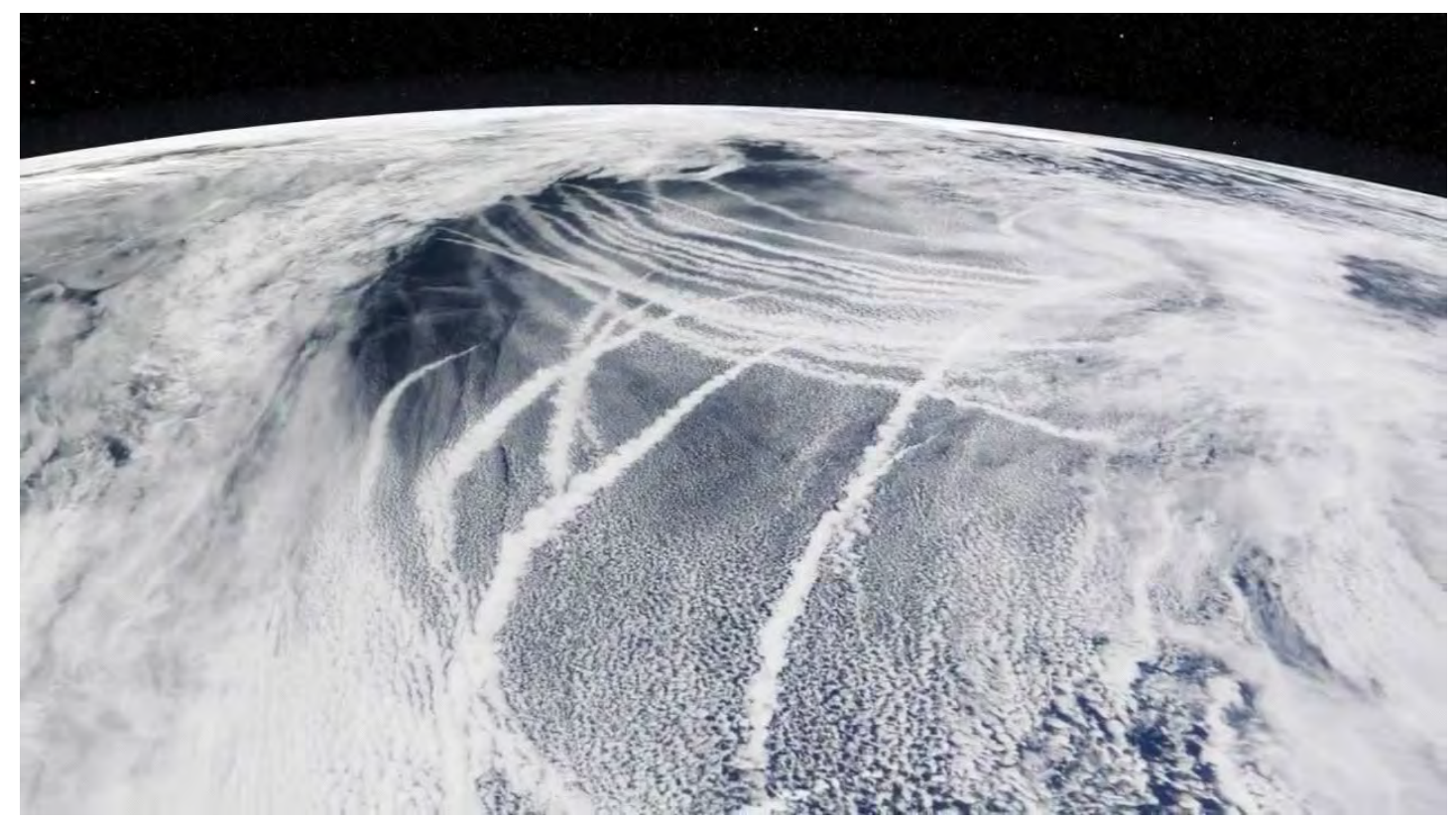

Figure 5 This satellite image illustrates how the emissions from ships alter cloud properties. The bright, linear clouds are those that have formed from particles emitted from ships.

The ship track example is only one of many where human activities have clearly been proven to alter cloud properties, leading us to conclude that human induced weather modification is not only possible, but is happening inadvertently on many scales in many places.

\section{Major Obstacles to Effective Cloud Seeding}

The three major obstacles that cloud seeding efforts must overcome are: 1 ) validation, 2) scale and 3) avoiding negative impacts. The first obstacle, that of validation, is a barrier only if you are a serious scientist who wishes to honestly evaluate if seeding applied to a cloud system brought about the intended effect. The working hypothesis that must be tested is "Are the effects produced by the cloud seeding significantly different than had no seeding been implemented?".

The problem that has been encountered by every cloud seeding program in 
the past is the natural variability of cloud formation and evolution. Regardless of how you assess if the cloud system responded to seeding, the conundrum is "Would the cloud have behaved in the observed way if you hadn't seeded it?". Hence, most scientifically legitimate seeding programs must rely on statistical analysis of many seeding events over multiple years to assess if a seeding signature can be extracted from the large data set.

The second obstacle, that of scale, concerns the volume of the system that is being seeded compared to volume of seeding material being dispersed. The cloud systems that are being seeded are usually, at a minimum, several hundred meters to tens of kilometers wide with depths from bases to tops of 500 to $5000 \mathrm{~m}$. These dimensions represent cloud volumes ranging from 125 million to 500 billion cubic meters.

Compare these dimensions, for example, with those of the seeding material being dispersed by an aircraft along a thin line at cloud base. If the aircraft manages to seed over a distance of 10 kilometers, the seeding material, at best, will fill a volume along that line of about 10,000 cubic meters, i.e. c.a. $0.000001 \%$ of even the smallest cloud volume.

Researchers are well aware of this obstacle; however, the theoretical argument is that the seeding produces a chain reaction that propagates and increases the impact by several orders of magnitude.

The third obstacle, and the one that is literally "the elephant in the room" is the potential for causing the opposite of the intended effect with the seeding, i.e. instead of increasing rain, you suppress it. Instead of decreasing hail you augment it. Modeling studies have shown that such negative effects are a reality, yet one that does not get enough attention when seeding activities are planned and executed.

\section{Feasibility}

The clear evidence of how human activities can modify clouds shows that weather modification is indeed feasible, even when unintended. The obstacles for scientifically controlled seeding, however daunting, are not insurmountable. If scientific methods are applied, and if measurements with high quality sensors are used to properly characterize cloud properties prior to seeding, then seeding material dispensed at the right time and the right place can, theoretically, bring about the desired effects.

Hence, in conclusion, although there are many myths that surround the science of cloud seeding, there remains great potential for this approach to be beneficial in improving crop yields and mitigating the adverse effects of weather once cloud processes are better understood and the appropriate level of scientific and technical resources invested. Given the increasing frequency of extreme events that are clearly linked to climate change, it would be unwise not to invest such resources in approaches such as cloud seeding 
that could help offset the environmental impact that these extreme events have.

\section{References and further reading}

Brimner, L.D.: 2015: The Rain Wizard: The Amazing, Mysterious, True Life of Charles Mallory Hatfield, Calkins Creek Publishers, 80 pp. (Young adults reading).

Butree, J. M.: 1930: The Rhythm of the Redman: in Song, Dance and Decoration. New York, A. S. Barnes,

Fleming, J. R., 2010. Fixing the Sky: The Checkered History of Weather and Climate Control.Columbia U. Press, New York. 325 pp.

Harper, K. C., 2017. Make it Rain: State Control of the Atmosphere in Twentieth Century America. U. of Chicago Press, Chicago. 317 pp.

Havens, B. S., J. E. Jiustoand B. Vonnegut, 1979. Early History of Cloud Seeding. Atmospheric Sciences Research Center, State University of New York at Albany. $75 \mathrm{pp}$.

Schaefer, V., 1968: The early history of weather modification, Bulletin of the American Meteorological Society, 49, 337-342. 